\title{
Whole Grain Gluten-Free Vegetable Spicy Snacks
}

\author{
Talwinder S. Kahlon ${ }^{1}$, Roberto J. Avena-Bustillos ${ }^{2}$, Mei-Chen M. Chiu ${ }^{1} \&$ Marlene B. Hidalgo ${ }^{1}$ \\ ${ }^{1}$ Western Regional Research Center, USDA-ARS, 800 Buchanan St, Albany, CA 94710, USA \\ ${ }^{2}$ University of California, Davis, CA, USA \\ Correspondence: Talwinder S. Kahlon, Western Regional Research Center, USDA-ARS, 800 Buchanan St, \\ Albany, CA 94710, USA. Tel: 1-(510)-559-5665. E-mail: Talwinder.Kahlon@ars.usda.gov
}

Received: June 24, 2015 Accepted: July 25, 2015 Online Published: August 17, 2015

doi:10.5539/jfr.v4n5p57 URL: http://dx.doi.org/10.5539/jfr.v4n5p57

\begin{abstract}
Four kinds of spicy snacks (gluten-free, whole grains with fresh vegetables, low in fat, sugar and salt) were evaluated. Acceptance of spicy snacks tested was Carrot-Garlic 77\%, Broccoli-Garlic 68\%, Spinach-Garlic 61\% and Red Onion 53\%. This is the first report of spicy gluten-free, 50\% vegetable snacks, which offer a nutritional snack choice for all and an option for gluten sensitive individuals. In addition, it offers spicy snacks that would encourage low fat, sugar and salt foods more palatable and increased health promoting vegetable consumption. The snacks reported herein can be prepared in any house kitchen and/or commercial production. These crispy snacks would have desirable microbial stability resulting in longer shelf life. Each $30 \mathrm{~g}$ serving of these healthy chips would provide 1.2-1.3 $\mathrm{g}$ of dietary fiber. Currently available chips in the market contain up to twice as much salt as the chips reported herein. These gluten-free vegetable spicy chips could be considered good source of dietary fiber and potassium.
\end{abstract}

Keywords: carrot, broccoli, gluten-free, snacks, spinach, red onion, whole grain

\section{Introduction}

Snacks play a significant role in family as well as public events. In children increases is snacking have been in salty and sugary products (Piernas \& Popkin, 2010). In the efforts to promote healthfulness of our diets, whole grain foods and savory snacks have been reported (Smith et al., 2013, Kahlon et al., 2014). Low dietary fat, sugar and salt intake is highly recommended to reduce obesity related lifestyle diseases. Since food flavors are fat soluble, low fat foods are not as tasty as high fat flavorful foods. Spicy healthy snacks would make low fat, sugar and salt foods more palatable. Serving healthy snacks to children at home and in school programs would develop eating habits that would prevent obesity and premature degenerative diseases later in life. It is recommended that at least one/half of all the grains eaten should be whole grains (Nutrition Policy and Promotion; Dietary Guidelines for Americans, USDA, 2010). Healthy products should incorporate whole grains instead of refined grains. Eating whole grains lowers the risk many life style chronic diseases (Whole Grain Council, 2009). Consuming 3 servings of whole grain have been reported to results in significant health benefits. Foods containing more than one/half whole grains and providing one/third daily requirement of dietary fiber are allowed label health claims (US Food and Drug Administration, 2003), http://www.fda.gov/Food/LabelingNutrition/LabelClaims/FDAModernization ActFDAMAClaims/ucm073634.htm). Gluten-free snacks are needed as hypersensitivity to gluten has been increasing in the world. In order to meet desired amount of vegetables in daily diets snacks containing vegetables would be desirable. Gluten-free products are considered health promoting with a clean label. In a family even if one member is gluten sensitive (with celiac disease) the whole family needs to remove gluten products from the house. However, food and snacks available in US contain high salt, fat and simple sugar and would be considered unhealthy (Mother-Jones, 2012). Home cooked and commercially offered foods and snacks need to be health promoting gluten-free, vegetable spicy snacks. Acceptance of gluten-free savory snacks containing $50 \%$ vegetables have been reported to be Carrot 88\%, Broccoli 77\%, Spinach 68\% and Red Onion 65\% (Kahlon et al., 2014). Currently there are many spicy snacks available in the market high in salt, sugar and fat. There is a need for gluten-free healthy spicy snacks to meet changing demographics and ethnic character of the world population. Spicy healthy whole grain gluten-free snacks would make lower salt, sugar and fat foods more palatable. In the study reported herein, sixty two in house volunteers evaluated four kinds of low fat, sugar and salt spicy snacks containing gluten-free whole grains and fresh vegetables. 


\section{Materials and Methods}

\subsection{Preparation}

All the ingredients were purchased from local markets. Brown rice flour was obtained by pin-milling whole grains rice (160Z, Alpine Pin Mill). The composition of the ingredients is listed in Table 1. Brown rice and sorghum samples were analyzed for nitrogen, using AOAC method 990.03 (2000) by Leco FP628 analyzer (Leco Corporation, St Joseph, MI); total dietary fiber, using AOAC method 985.29 (2000), crude fat with petroleum ether and an accelerated solvent extractor (ASE 350, Dionex Corp.); ash, using AOAC method 942.05 (1990); and moisture, using AOAC method 935.29 (1990).

Table 1. Ingredient composition of the gluten-free whole grain vegetable snacks dry matter (DM) basis, \%

\begin{tabular}{lllllll}
\hline Ingredients & Protein & Fat & Minerals & Carbohydrate & TDF & DM \\
\hline Brown Rice & 9.04 & 7.24 & 1.1 & 82.62 & 3.08 & 88.94 \\
Sorghum & 8.63 & 3.44 & 1.45 & 86.48 & 6.63 & 90.67 \\
Tapioca flour & -- & --- & --- & 100 & -- - & 96.15 \\
Potato Flakes & 8.34 & 0.41 & 1.45 & 81.17 & 6.6 & 93.42 \\
Carrots, fresh & 7.94 & 2.05 & 4.01 & 86 & 23.91 & 11.71 \\
Broccoli, fresh & 26.36 & 3.46 & 4.52 & 65.66 & 24.3 & 10.7 \\
Spinach, fresh & 33.26 & 4.53 & 10.08 & 52.13 & 25.58 & 8.6 \\
Red Onion, fresh & 10.1 & 0.92 & 3.12 & 85.86 & 15.61 & 10.89 \\
Garlic, fresh & 15.35 & 1.21 & 1.88 & 81.56 & 5.07 & 41.42 \\
Cayenne Pepper & 13.06 & 18.78 & 2.88 & 65.28 & 29.58 & 91.95 \\
\hline
\end{tabular}

Brown Rice and Sorghum were analyzed by AOAC $(1990,2000)$. Nitrogen to protein factors used were brown rice 5.95 and sorghum 6.25 (4). Total Dietary Fiber, TDF; Dry matter, DM. Carbohydrate $=[100-($ Protein + fat + Ash)].

Tapioca flour data from product label.

Vegetables values from USDA Nutrient data base (http://ndb.nal.usda.gov/ndb/search/list).

\subsection{Formulation}

Spicy snack formulation contained gluten-free whole grains (base formulation) and fresh vegetable (1:1) as is basis. Table 2 shows the base formulation composition. The vegetable used were fresh carrots, broccoli, spinach, red onion and garlic. Table 3 shows the composition of the whole grain gluten-free vegetable snacks. Snack dough was prepared by mixing ingredients in a KitchenAid table top mixer (KitchenAid Proline, St. Joseph, MI). Water was added slowly, it took about 4 minutes to thoroughly mix the ingredients. Snack dough was covered and held at room temperature for $30 \mathrm{~min}$. Two equal portions of snack dough (about $10 \mathrm{~g}$ each) were cooked for two minutes in 750 watts double 5 inch Krumkake Baker (CucinaPro.com) Figure 1. Cooked snacks were vacuum heat sealed in plastic bags by Food Saver 2200 Series (Foodsaver.com).

Table 2. Base mix of spicy gluten free snacks (As Is Basis)

\begin{tabular}{lllllllll}
\hline Ingredients & $\begin{array}{l}\text { Brown } \\
\text { Rice flour }\end{array}$ & $\begin{array}{l}\text { Sorghum } \\
\text { flour }\end{array}$ & Tapioca flour & $\begin{array}{l}\text { Mashed } \\
\text { Potato }\end{array}$ & Canola Oil & Guar gum & $\begin{array}{l}\text { Baking } \\
\text { powder }\end{array}$ & $\begin{array}{c}\text { Salt } \\
\text { Pepper }\end{array}$ \\
\hline$\%$ & 45 & 20 & 16.75 & 8 & 6 & 2 & 1.5 & 0.5 \\
\hline
\end{tabular}


Table 3. Composition of spicy gluten-free vegetable snacks (As Is Basis)

\begin{tabular}{lrrrr}
\hline Snack & Base Mix, g & Vegetable, g & Garlic, g & Water, mL \\
\hline Carrot-Garlic & 100 & 100 & 10 & 200 \\
Broccoli-Garlic & 100 & 100 & 10 & 200 \\
Spinach-Garlic & 100 & 100 & 10 & 200 \\
Red Onion & 100 & 100 & --- & 200 \\
\hline
\end{tabular}

All the vegetables and garlic were fresh, chopped.

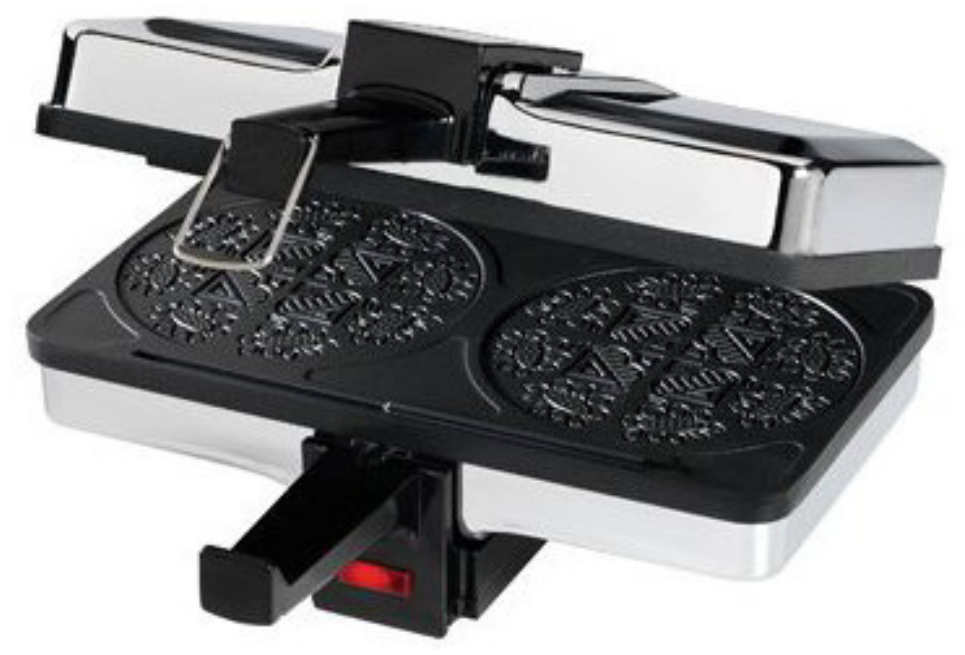

Figure 1. CucinaPro Krumkake Baker

\subsection{Sensory Evaluation of Snacks}

Sixty two in-house volunteers judged gluten free whole grain vegetable snacks for Color/Appearance, Odor/Aroma, Taste/Flavor, Texture/Mouth feel on a scale of $1-5$ (like very much $=5$, like slightly $=4$, neutral $=3$, dislike slightly $=2$, dislike very much $=1)$. The overall acceptable preference was on a scale of $1-2$ (acceptable $=2$, not acceptable $=1$ ).

\subsection{Water Activity}

Water activity (Aw) was measured at $25.01 \pm 0.02{ }^{\circ} \mathrm{C}$ by triplicate using an AquaLab dew point water activity meter 4TE (Decagon Devices, Inc., Pullman, WA).

\subsection{Texture}

Compression tests were done on $55 \mathrm{~mm}$ diameter flat snacks mounted between two $3.5 \times 3.5$ inch square, $1 / 4$ in thick, iron plates with 1 in diameter centered holes and puncturing over smooth and sound snack surfaces with 1.14 $\pm 0.17 \mathrm{~mm}$ thickness with a flat $3 \mathrm{~mm}$ diameter cylindrical probe attached to a TA-XT2i Texture Analyzer (Texture Technologies Corp., Scarsdale, NY) set at $1 \mathrm{~mm} / \mathrm{s}$ test speed and $2 \mathrm{~mm}$ rupture test distance. Temperature during testing was $18.7 \pm 0.3{ }^{\circ} \mathrm{C}$ and samples were tested right after opening vacuum sealed plastic bags used for packaging the snacks. Number of cracks, force needed for first crack, first crack area, maximum force and maximum force area were obtained by 10 replicates for each snack.

\subsection{Density}

The bulk density $\left(\rho_{b}\right)$ was obtained by triplicate from perfectly round flat snacks by weighing to the nearest $0.0001 \mathrm{~g}$ using an analytical balance and measuring the diameter and maximum and minimum thickness in five random places with a digital micrometer to the nearest $0.001 \mathrm{~mm}$ and averaged. True density $\left(\rho_{t}\right)$ was determined using an AccPyc II 1340 gas pycnometer (Micromeritics Instrument Co., Norcross, GA) at $21.4 \pm 0.4^{\circ} \mathrm{C}$. Samples of each snack were cut into small pieces and dried at room temperature for $15 \mathrm{~h}$ at $0 \%$ relative humidity in a vacuum desiccator with anhydrous calcium sulfate (W. A. Hammond Drierite, Xenia, OH). After drying, samples were compressed into a measuring cylinder for five true density measurements. 
Where: $\rho_{t}=$ true density; $\rho_{b}=$ bulk density.

\subsection{Statistical Analysis}

Data were analyzed with Minitab statistical software (version 14.12.0, Minitab Inc., State College, PA) by one-way analysis of variance and Tukey's multiple comparison tests with $(\mathrm{P} \leq 0.05)$ as criteria of significance.

\section{Results and Discussion}

Four kinds of whole grain gluten-free vegetable spicy snacks are shown in Figure 2. Fresh baked whole grain gluten-free low salt, low sugar and low fat vegetable spicy snacks were cooled to room temperature, before sealing in vacuum food saver packages. Color/Appearance of Broccoli-Garlic snacks was determined to be significantly $(\mathrm{P} \leq 0.05)$ better than Spinach-Garlic snacks (Table 4). Roasted brown appearance of Broccoli-Garlic snacks was preferred over greenish color of cooked Spinach-Garlic snacks. Red Onion snacks Odor/Aroma was significantly preferred compared with Spinach-Garlic snacks. Carrot-Garlic snacks Taste/Flavor and Acceptance was significantly higher than that of Red Onion snacks. Red Onion snack Texture/Mouth feel was significantly lower than other snacks tested. Acceptance of spicy snacks tested is shown as bar graph (Figure 3). Acceptance values for whole grain gluten-free vegetable spicy snacks were Carrot-Garlic, 77\%; Broccoli-Garlic, 68\%; Spinach-Garlic, $61 \%$ and Red Onion, 53\%. These acceptance values were 7-12\% lower than those reported for similar savory snacks (Kahlon et al., 2014). With the view that spicy snacks would make low sugar, salt and fat meals more palatable, acceptance reported herein for spicy healthy snacks is desirable and could be further enhanced with fortifications and/or processing. Any house kitchen or commercial production could make these health promoting naval gluten-free vegetable spicy snacks. These spicy snacks have the potential of increasing palatability of low sugar, salt and fat health promoting diets.

Table 4. Results of taste panel of brown rice - sorghum whole grain (gluten-free), vegetable, low salt spicy snacks $^{\text {abc }}$

\begin{tabular}{llllll}
\hline Gluten free & Color/ & Odor/ & Taste/ & Texture/ & Acceptance \\
Vegetable Snacks & Appearance & Aroma & Flavor & Mouth feel & \\
\hline Carrot-Garlic & $3.76 \pm 0.13^{\mathrm{ab}}$ & $3.42 \pm 0.08^{\mathrm{ab}}$ & $3.44 \pm 0.13^{\mathrm{a}}$ & $4.00 \pm 0.10^{\mathrm{a}}$ & $1.77 \pm 0.05^{\mathrm{a}}$ \\
Broccoli-Garlic & $4.05 \pm 0.12^{\mathrm{a}}$ & $3.34 \pm 0.10^{\mathrm{ab}}$ & $3.23 \pm 0.14^{\mathrm{ab}}$ & $3.77 \pm 0.12^{\mathrm{a}}$ & $1.68 \pm 0.06^{\mathrm{ab}}$ \\
Spinach-Garlic & $3.48 \pm 0.15^{\mathrm{b}}$ & $3.24 \pm 0.09^{\mathrm{b}}$ & $3.19 \pm 0.16^{\mathrm{ab}}$ & $3.97 \pm 0.12^{\mathrm{a}}$ & $1.61 \pm 0.06^{\mathrm{ab}}$ \\
Red Onion & $3.81 \pm 0.12^{\mathrm{ab}}$ & $3.53 \pm 0.10^{\mathrm{a}}$ & $2.97 \pm 0.14^{\mathrm{b}}$ & $3.26 \pm 0.12^{\mathrm{b}}$ & $1.53 \pm 0.06^{\mathrm{b}}$ \\
\hline
\end{tabular}

${ }^{\mathrm{a}}$ Values are mean $\pm \mathrm{SEM} ; \mathrm{n}=62$.

${ }^{\mathrm{b}}$ Color/Appearance, Odor/Aroma, Taste/Flavor and Texture/ Mouth feel were on a scale of 1-5 (Like very much = 5 , like slightly $=4$, neutral $=3$, dislike slightly $=2$ and dislike very much $=1$ ); Acceptance was on scale of 1-2 (Acceptable $=2$ and unacceptable $=1$ ).

${ }^{\mathrm{c}}$ Values within columns with different superscript letters differ significantly $(\mathrm{P} \leq 0.05)$.

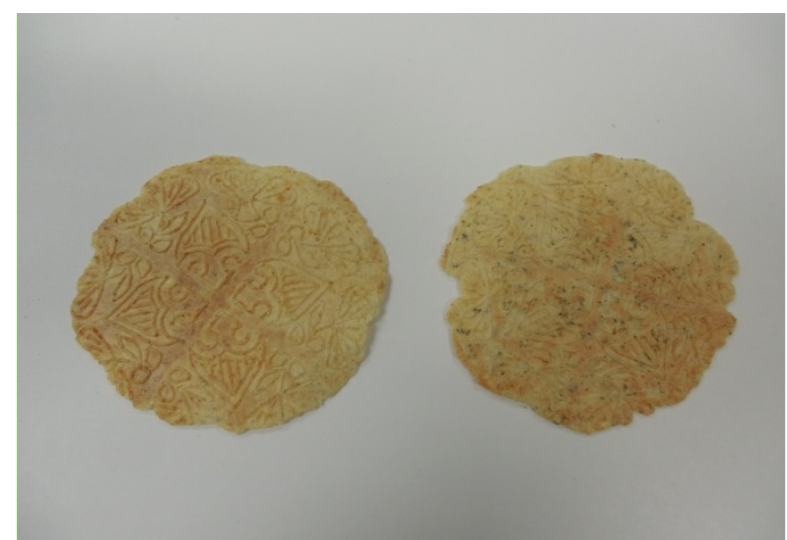

Carrot-Garlic
Broccoli-Garlic

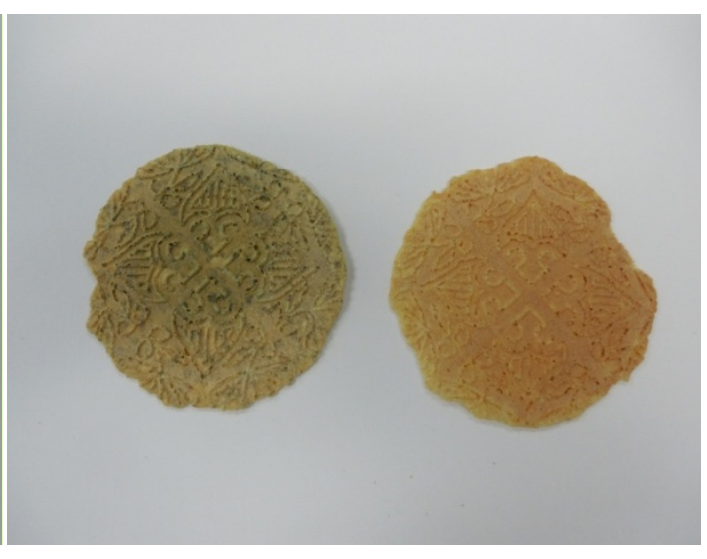

Spinach-Garlic
Red Onion

Figure 2. Spicy snacks are shown (left to rights), Carrot-Garlic, Broccoli-Garlic, Spinach-Garlic and Red Onion 


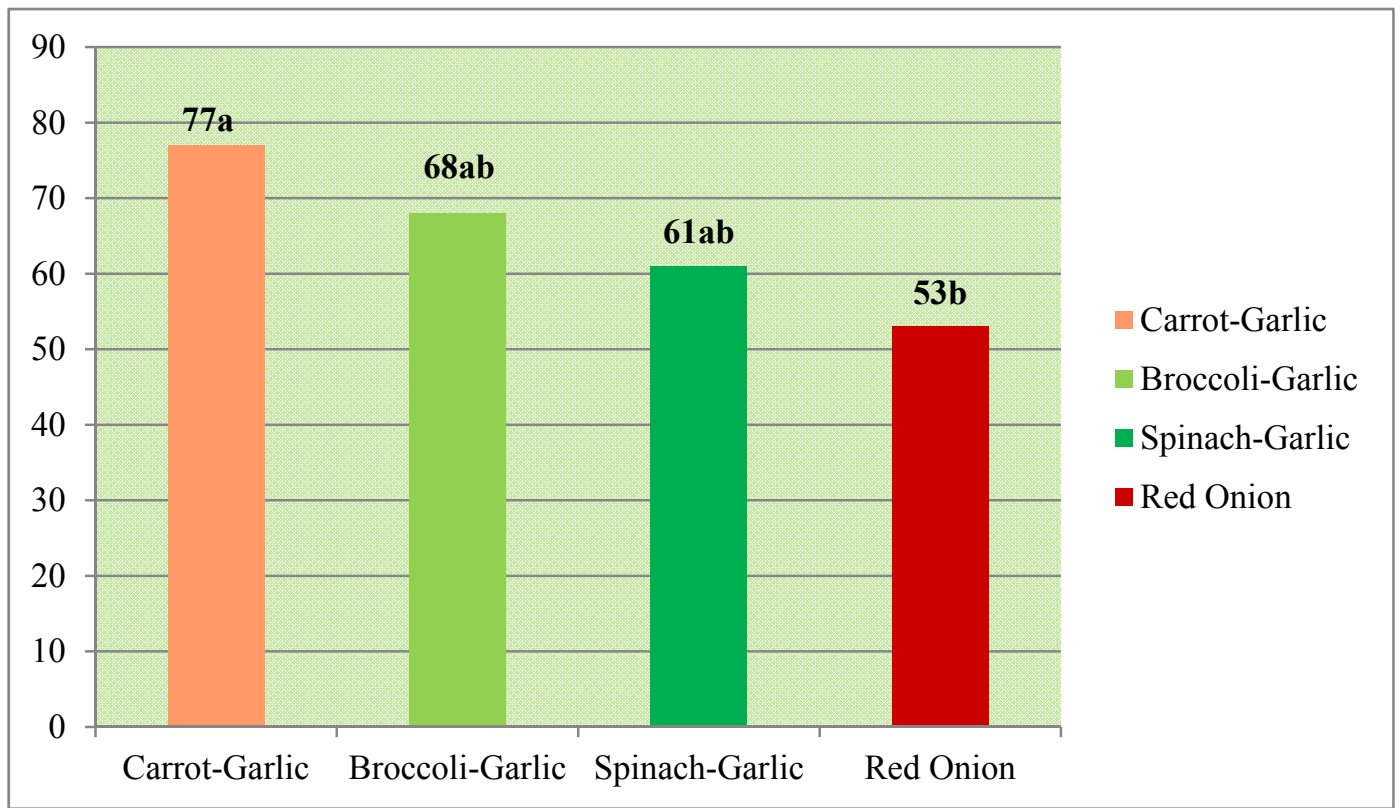

Bars with different letters differ significantly $(\mathrm{P} \leq 0.05)$.

Figure 3. Panelist acceptance \% for whole grain, gluten-free vegetable, carrot-garlic, broccoli-garlic, spinach-garlic and red onion spicy snacks

\subsection{Water Activity}

Water activity (Aw) of four kinds of snacks tested was significantly different from each other Broccoli-Garlic $>$ Red Onion $>$ Carrot-Garlic $>$ Spinach-Garlic (Table 5). Water activity values ranged from 0.20-0.27. These Aw values are typical of very crispy snacks (Katz and Labuza 1981). Carrot snacks with Aw 0.44 have been reported as crisp and with desired microbial stability (Adams and Moss 1997; Dueik et al., 2013).

Table 5. Water Activity, Texture and Density Brown Rice - Sorghum Whole Grain (Gluten-Free), Vegetable, Low Salt Spicy Snacks ${ }^{\text {ab }}$

\begin{tabular}{llllll}
\hline $\begin{array}{l}\text { Gluten free } \\
\text { Vegetable Snacks }\end{array}$ & Water Activity & $\begin{array}{l}\text { Texture } \\
\text { (Newtons) }\end{array}$ & $\begin{array}{l}\text { Density } \\
\mathrm{g} / \mathrm{ml}\end{array}$ & $\begin{array}{l}\text { Bulk density } \\
\mathrm{g} / \mathrm{ml}\end{array}$ & Porosity \\
\hline Carrot-Garlic & $0.240 \pm 0.002^{\mathrm{c}}$ & $3.527 \pm 0.174^{\mathrm{b}}$ & $1.406 \pm 0.001^{\mathrm{a}}$ & $0.295 \pm 0.010^{\mathrm{d}}$ & $0.790 \pm 0.001^{\mathrm{a}}$ \\
Broccoli-Garlic & $0.273 \pm 0.008^{\mathrm{a}}$ & $2.564 \pm 0.217^{\mathrm{c}}$ & $1.371 \pm 0.001^{\mathrm{d}}$ & $0.328 \pm 0.004^{\mathrm{b}}$ & $0.761 \pm 0.001^{\mathrm{c}}$ \\
Spinach-Garlic & $0.201 \pm 0.006^{\mathrm{d}}$ & $3.525 \pm 0.309^{\mathrm{b}}$ & $1.396 \pm 0.001^{\mathrm{c}}$ & $0.341 \pm 0.006^{\mathrm{a}}$ & $0.756 \pm 0.001^{\mathrm{d}}$ \\
Red Onion & $0.258 \pm 0.002^{\mathrm{b}}$ & $4.331 \pm 0.140^{\mathrm{a}}$ & $1.399 \pm 0.001^{\mathrm{b}}$ & $0.308 \pm 0.003^{\mathrm{c}}$ & $0.780 \pm 0.001^{\mathrm{b}}$ \\
\hline
\end{tabular}

${ }^{a}$ Values are mean \pm SEM; Values are mean of triplicate analysis for water activity $(n=3)$, texture, $(n=10)$ and density $(\mathrm{n}=5)$.

${ }^{\mathrm{b}}$ Values within columns with different superscript letters differ significantly $(\mathrm{P} \leq 0.05)$.

Porosity $=1-\left(\rho_{\text {bulk }} / \rho_{\text {true }}\right)$

\subsection{Texture}

Red Onion snack texture was significantly higher than Carrot-Garlic and Spinach-Garlic snacks (Table 5). Texture values for Carrot-Garlic and Spinach-Garlic were similar and significantly higher than those for Broccoli-Garlic snacks. Data suggest that crispiness for the snacks tested was Red Onion $>$ Carrot-Garlic $=$ Spinach-Garlic $>$ Broccoli-Garlic. Previously similar texture of savory snacks of Red Onion, Carrot and Spinach and significantly higher than that of Broccoli have been reported (Kahlon et al., 2014). Data suggest that spicy formulation lowered 
crispiness of Carrot-Garlic and Spinach-Garlic snacks but did not change relative crispiness of Red Onion or Broccoli-Garlic snacks.

\subsection{Density ( $\left.\rho_{\text {true }}\right)$}

There were significant differences in the true density of the gluten-free spicy vegetable snacks tested (Table 5). Values were Carrot-Garlic $>$ Red Onion $>$ Spinach-Garlic $>$ Broccoli-Garlic. True density of Carrot-Garlic and Red Onion snacks was consistent with higher dry matter content of these two vegetable (Table 1). However, Spinach-Garlic snacks had significantly higher density than Broccoli-Garlic snacks even with $20 \%$ lower dry matter in spinach than broccoli.

\subsection{Bulk Density ( $\left.\rho_{\text {bulk }}\right)$}

Bulk density values were significantly different among the gluten-free spicy vegetable snacks tested (Table 5). Bulk density values were Spinach-Garlic $>$ Broccoli-Garlic $>$ Red Onion $>$ Carrot-Garlic.

\subsection{Porosity}

Porosity was calculated using the equation [Porosity $\left.=1-\left(\boldsymbol{\rho}_{\text {bulk }} / \boldsymbol{\rho}_{\text {true }}\right)\right]$. Porosity values were significantly different among the four gluten-free spicy vegetable snacks tested (Table 5). Values were Carrot-Garlic $>$ Red Onion $>$ Broccoli-Garlic $>$ Spinach-Garlic. Porosity values were inversely related to the bulk density values of these snacks.

\subsection{Expansion Values}

Expansion values can be calculated [Expansion Value $=1 /(1-$ Porosity $\left.)=\boldsymbol{\rho}_{\text {true }} / \boldsymbol{\rho}_{\text {bulk }}\right)$. Expansion values (fluffiness) of the four gluten-free spicy vegetable snacks tested were Carrot-Garlic, 4.8; Broccoli-Garlic, 4.2; Spinach-Garlic, 4.1 and Red Onion, 4.5. The four snacks tested had desirable expansion of 4-5, suggesting that these snacks would encourage lower caloric consumption and would give desired presentation in commercial packaging.

\section{Conclusions}

Any house kitchen or commercial production can prepare these naval health promoting gluten-free, vegetable low salt, low sugar and low fat spicy snacks. Spicy snack would make low fat, low sugar and low salt foods more palatable. Acceptability of spicy snacks evaluated by in house volunteers $(n=62)$ was Carrot-Garlic $77 \%$, Broccoli-Garlic 68\%, Spinach-Garlic 61\% and Red Onion 53\%. These crispy snacks had desirable microbial stability that would result in longer shelf life. Each $30 \mathrm{~g}$ serving of these healthy snacks would provide $1.2-1.3 \mathrm{~g}$ of dietary fiber. These snacks contain $33-50 \%$ less salt and have no added sugar than most chips currently available in the market. One serving of these spicy chips is a good source of dietary fiber and potassium.

\section{References}

Adams, M. R., \& Moss, M. O. (1997). Food microbiology. Cambridge: The Royal Society of Chemistry.

Agricultural Research Service, United States Department of Agriculture, National Nutrient Database for Standard Reference Release 26 (http://ndb.nal.usda.gov/ndb/search/list).

AOAC. (1990). Official Methods of Analysis of the Association of Official Analytical Chemists (15th ed., pp. 70, 725, 1st Suppl. p. 83). The Association: Arlington VA.

AOAC. (2000). Official Methods of Analysis of the Association of Official Analytical Chemists (17th ed., Chap. 45, pp. 78E-80). The Association: Arlington, VA.

Dueik, V., Marzullo, C., \& Bouchon, P. (2013). Effect of vacuum inclusion on the quality and the sensory attributes of carrot snacks. Food Science and Technology, 50, 361-365. http://dx.doi.org/10.1016/j.lwt.2012.05.011

Food and Drug Administration. (2003). Retrieved from http://www.fda.gov/Food/LabelingNutrition/LabelClaims/FDAModernizationActFDAMAClaims/ucm073634.ht $\mathrm{m}$

Kahlon, T. S., Avena-Bustillos, R. J., Chiu, M. M., \& Hidalgo, M. B. (2014). Whole Grain Gluten-Free Vegetable Savory Snacks. Journal of Food Research, 3, 1-7. http://dx.doi.org/10.5539/jfr.v3n5p1

Katz, E. E., \& Labuza, T. P. (1981). Effect of water activity on the sensory crispness and mechanical deformation of snack food products. Journal of Food Science, 46, 403-409. http://dx.doi.org/10.1111/j.1365-2621.1981.tb04871.x 
$\begin{array}{lll}\text { Mother } \quad \text { Joes. } & \text { Retrieved fol2). }\end{array}$ http://www.motherjones.com/blue-marble/2012/01/america-food-spending-less

New Product Trends. (2015). Sports Drinks, Nutrition Bars Reshape Market. Retrieved from PreparedFoods.com

Piernas, C., \& Popkin, B. M. (2010). Trends in snacking among U. S. children. Health Affairs, 29, 398-404. http://dx.doi.org/10.1377/hlthaff.2009.0666

Smith, L. P., Ng, S. W., \& Popkin, B. M. (2013). Trends in US home food preparation and consumption: Analysis of national nutrition surveys and time use studies from 1965-1966 to 2007-2008. Nutrition Journal, 12, 45-53. http://dx.doi.org/10.1186/1475-2891-12-45

UN.A.F.P.A. Statistics. (2012). Retrieved from http://www.pasta-unafpa.org/ingstatistics5.htm

US Food and Drug Administration. (2003). Retrieved from http://www.fda.gov/Food/LabelingNutrition/LabelClaims/FDAModernizationActFDAMAClaims/ucm073634.ht $\mathrm{m}$.

USDA. (2010). Center for Nutrition Policy and Promotion; Dietary Guidelines for Americans. Retrieved from http://www.choosemyplate.gov/

Whole Grain Council. (2009). Retrieved from http://www.wholegrainscouncil.org/

\section{Copyrights}

Copyright for this article is retained by the author(s), with first publication rights granted to the journal.

This is an open-access article distributed under the terms and conditions of the Creative Commons Attribution license (http://creativecommons.org/licenses/by/3.0/). 